\title{
Sri Lanka Elderly Study: Phase 1 (SLES:1) - A descriptive study of the health status and physiological parameters of institutionalized elderly in Colombo district: The protocol
}

\section{SLES Research team}

\begin{abstract}
Amarasiri W A D L*1, Atapattu P M1, Dalpatadu K P C ${ }^{1}$, Dissanayake W D N11, Fernando A D A1, Fernando N H D ${ }^{1}$, Gunatilake $\mathbf{M}^{1}$, Jayawardena $\mathbf{R}^{1,2}$, Jayaweera $\mathbf{S} \mathbf{K}^{1}$, Kumarasiri M A H $\mathbf{P}^{1}$, Ranawaka $\mathbf{H} \mathbf{A} \mathbf{R}^{1}$, Sathkumara B L ${ }^{1}$, Thisera H C C ${ }^{1}$, Udagedara U A H ${ }^{1}$, Upekshani A V N N 1 , Vamasiwan $\mathbf{N}^{1}$, Vithanage $\mathbf{K}^{1}$, Waidyarathne A O K ${ }^{1}$, Wanninayake W M L V1, Wasalathanthri $\mathbf{S}^{1}$, Wickramasinghe $\mathbf{N}^{1}$
\end{abstract}

Journal of the Ceylon College of Physicians, 2019, 50, 34-40

Key words: elderly population, elderly homes, geriatric health

\begin{abstract}
Objectives: Population ageing is a world phenomenon affecting many sectors including health. High prevalence of multiple co-morbidities, increased healthcare expenditure, psychological disease and social consequences are some major health problems of ageing. Study of physiology and health status among elders is an important component in geriatric care. This is a study protocol to describe overall health status and functional capacity among the elders in residential care facilities in Colombo district.
\end{abstract}

Methods: Eligible elders aged over 65 years, in all residential care facilities in Colombo district, registered under the $\mathrm{N}$ ational Secretariat for elders will be included in this cross-sectional study. Data on basic demography and medical co-morbidities will be collected. Nutritional status will be assessed by 24 -hour dietary recall, mini nutritional assessment and anthropometric measurements. Five fried model indicators, Montreal cognitive assessment and geriatric depression scale will be used to assess frailty, depression and cognition respectively. Timed up and go test and five times sit to stand test will be performed to assess the risk of falls and the FRAX index for osteoporotic risk assessment. Spirometry

\footnotetext{
${ }^{1}$ Department of Physiology, Faculty of Medicine, University of Colombo, Colombo, Sri Lanka.

2 Institute of Health and Biomedical Innovation, Queensland University of Technology, Brisbane, Australia.
}

will be used to assess respiratory function. Descriptive and correlation analysis of data will be performed.

Discussion: This is a comprehensive health assessment of the elderly population living in residential care facilities for elders in Colombo. The study will contribute to establish better geriatric care in Sri Lanka and will serve as a model to design an island wide study on elderly.

\section{Introduction}

There is an increase in the ageing population globally. It was $48 \%$ in 2015 compared toyear 2000 , reaching 901 million from 607 million. The population over 60 years is expected to reach 2.1 billion by 2030(1). An increased elderly population leaning towards living in residential elderly care centres has become one of the most significant social transformations of the $21^{\text {st }}$ century with implications for nearly all sectors of the society ${ }^{1}$. The health sector is among the most important sectors catering to the needs of the elderly population due to the high burden of health issues with ageing.

Multiple co-morbidities are a common health related issue among the elderly population. The prevalence of heart disease has increased among the older population². The probability of having chronic comorbid diseases such as arthritis, osteoporosis, diabetes and hypertension too has increased in the older population over the past few decades ${ }^{3}$. Comorbidities and physiological changes have compromised the ability of the elderly population to 
cope with acute stressors thus making them frail ${ }^{4,5}$. Between $25 \%$ to $50 \%$ people older than 85 years are estimated to be frail, and they have a substantially increased risk of falls, disability, need for long-term care, and death ${ }^{4,5}$. The co morbidities, frailty and other changes with ageing population has resulted in several psychosocial problems. All these problems affect Sri Lanka too.

In Sri Lanka, the population over 60 years has increased from $6.6 \%$ in 1981 to $12.4 \%$ by 2012 and if the same rate of ageing continues, it is expected that the population aged over 60 years will reach $24.8 \%$ by $2041^{6}$. The prevalence of chronic disease in the population aged 60 and above was $45.3 \%$. The prevalence of obesity which is a feature of metabolic syndrome leading to non-communicable diseases such as diabetes is also high in the older age group in Sri Lanka ${ }^{8}$. Recurrent falls, depression, cognitive dysfunction and severe visual impairment were some of the unnoticed illnesses present in a substantial proportion of elders ${ }^{9}$. It has also been reported that over $50 \%$ of elderly in some elderly care institutes in Sri Lanka are malnourished ${ }^{10}$. The details on dietary diversity scoring and the serving sizes among the elderly are deficient ${ }^{11}$. Despite the glimpses of these graver health and economic consequences of ageing population in the country, a comprehensive study of the elderly population has not been conducted.

This study would be a comprehensive health assessment to describe the overall health status and functional capacity of the elderly population living in the residential care facilities in the Colombo district in Sri Lanka.

\section{Methods}

This cross-sectional descriptive study will be conducted in the residential care facilities registered in the National Secretariat for Elderly in Colombo district. The ethical clearance for this study was obtained from the Ethics Review Committee of Faculty of Medicine, University of Colombo (EC 17-048). Elders over 65 years of age will be included in this study, and those who are unable to communicate due to hearing, speech and visual impairments will be excluded. Though some of the parameters may be checked in individuals with those parameters it was considered unethical to carry out tests without properly communicating the procedure.

Residents who are not able to mobilize, those with neurodegenerative disease (e.g: Alzheimer disease, Parkinson disease), stroke, elderly people who have moderate to significant impairment with activities of daily living, as determined by interview will be excluded when assessing tendency to fall using timed up and go test and five time fit to stand test.

Residents with cognitive impairment that interferes with ability to comply with instructions and contraindication to spirometry [active respiratory infection, history of IHD, uncontrolled hypertension, history of haemoptysis, history of pneumothorax, history of pulmonary embolism, any patient discomfort, vomiting, diarrhoea, common cold, history of thoracoabdominal surgery] will be excluded from spirometry.

The data will be collected through a questionnaire administered by well-trained data collectors and a series of internationally accepted tests conducted by trained technical officers using calibrated equipment.

Basic demography, nutritional assessment, physical activity will be assessed using the interviewer administered questionnaire. The basic facilities available in the residential elderly care facilities will be collected from the heads of the institutes.

Basic demography details such as age, marital status, past occupations and support systems will be gathered. The details related to existing co-morbidities and the medications they are currently on will be gathered from the participants and by their existing medical records.

The diet of the residents will be assessed using a 24-hour dietary recall. Food portion sizes will be obtained using standard household measures such as plate, bowl, cup, glass and different spoons. The mini nutritional assessment which is a widely used tool to assess malnutrition in the elderly will also be used to describe the nutritional status of the elders ${ }^{12}$.

Assessment of physical activity will be done using the physical activity scale for elderly (PASE); which is validated as a suitable tool to assess physical activity of elderly in community studies ${ }^{13}$ and the short version of the International physical activity questionnaire (IPAQ); a validated tool to measure physical activity levels of adults in community studies, which has been used in previous studies in Sri Lankan population ${ }^{14,15}$.

\section{Anthropometric measurements}

All anthropometric measurements will be performed following the standard protocols of the International Society for the Advancement of Kinanthropometry $\left(\right.$ ISAK) ${ }^{16}$. All anthropometric measurements will be performed under direct supervision of an ISAK level 1 anthropometrist. 
Table 1. Tools that will be used in the assessment of different components in SLES 1

\begin{tabular}{l|l}
\hline Component & Tool that will be used for assessment \\
\hline Nutritional status & $\begin{array}{l}\text { 24-hour dietary recall } \\
\text { Mini nutritional assessment (MNA) } \\
\text { Physical activity scale for elderly (PASE) } \\
\text { International physical activity questionnaire (IPAQ) } \\
\text { Height, Weight, } \\
\text { Body composition }\end{array} \quad \begin{array}{l}\text { Circumference: waist, hip, mid upper arm, calf skinfold thickness. } \\
\text { Frailty }\end{array} \quad \begin{array}{l}\text { Five fried model } \\
\text { Osteoporotic and fracture risk }\end{array}$ \\
Tendency to fall & $\begin{array}{l}\text { FRAX index } \\
\text { Timed up and go (TUG) test }\end{array}$ \\
Cognitive assessment & Five times sit to stand test (FTSST) \\
Risk of depression & Montreal cognitive assessment (MoCA) \\
Cardio respiratory function & Geriatric depression score - short form (GDS-S) \\
& Blood pressure (seated and standing) \\
\hline
\end{tabular}

Height will be taken to the nearest $0.1 \mathrm{~cm}$, as the maximum distance to the uppermost position on the head from heels, with the individual standing barefoot and in full inspiration using a stadiometer.

Body weight will be measured to the nearest 0.1 $\mathrm{kg}$ using a digital weighing scale with the participants wearing indoor light clothing.

Waist circumference will be measured midway between the iliac crest and the lower rib margin at the end of normal expiration using a plastic flexible tape to the nearest $0.1 \mathrm{~cm}$.

Hip circumference will be measured at the widest level over the greater trochanters using a plastic flexible tape to the nearest $0.1 \mathrm{~cm}$.

The measuring point of mid upper arm circumference (MUAC) will be marked at the midpoint between the acromion and the olecranon process in the right upper arm when the right elbow is 900 flexed placing the forearm palm down across the trunk. The measurement at the marked site will be taken using a plastic flexible tape to the nearest $0.1 \mathrm{~cm}$ when the right arm is extended alongside the body with the palm facing upwards.

The largest circumference of the calf will be measured as the calf circumference using a plastic flexible tape to the nearest $0.1 \mathrm{~cm}$ in seated/supine position when the knee and hip are $90^{\circ}$ flexed in the two lower limbs.

\section{Skinfold thickness}

Each skin fold measurement will be taken in duplicate on the non-dominant side, and the average of the two readings will be recorded using a consistent technique and by a calibrated Harpenden skinfold calliper.

a) Biceps skinfold site: The skinfold measurement will be taken parallel to the long axis of the arm at the biceps skinfold site at the point on the anterior surface of the arm in the mid-line at the level of the midacromial-radial landmark. This point will be located by projecting the mid-acromial-radial site perpendicularly to the long axis of the arm around to the front of the arm, and intersecting the projected line with a vertical line in the middle of the arm when viewed from the front. The participant will stand with the right arm relaxed, the shoulder externally rotated, and the elbow extended by the side of the body.

b) Triceps skinfold site: The skinfold measurement will be taken parallel to the long axis of the arm at the triceps skinfold site, the point on the posterior surface of the arm, in the mid-line, at the level of the marked mid-acromial-radial landmark. This point is located by projecting the mid-acromial-radial site perpendicularly to the long axis of the arm around to the back of the arm, and intersecting the projected line with a vertical line in the middle of the arm when viewed from behind. The participant will stand with the arm hanging by the side in the mid-prone position and the elbow extended by the side of the body. 
c) Subscapular skinfold site: The skinfold will be measured at the site $2 \mathrm{~cm}$ along a line running laterally and obliquely downward from the subscapular landmark, the under most tip of the inferior angle of the scapula, at a $45^{\circ}$ angle. The line of the skinfold is determined by following the natural fold lines of the skin. The participant will be with the arms hanging by the sides.

d) Medial calf skinfold site: The skinfold measurement will be taken vertically at the medial calf skinfold site at the maximum girth level. The participant will stand with their right foot placed on a box and the calf relaxed. The fold was parallel to the long axis of the leg. The right knee will be bent at about $90^{\circ}$ angle.

\section{Blood pressure measurement}

Seated blood pressure will be measured after at least a 10-minutes rest using Riester digital blood pressure monitor (Rudolf Riester, Germany). Blood pressure in standing position after 3 minutes of standing will also be measured to assess orthostatic hypotension, which is defined as a fall in systolic blood pressure greater than $20 \mathrm{~mm} \mathrm{hg}$ or a fall in diastolic blood pressure greater than $10 \mathrm{~mm}$ hg within 3 minutes of standing ${ }^{17}$.

\section{Assessment of frailty}

As per the five fried model indicator, presence of 3 positive indicators of the 5 indicators; weight loss, exhaustion, low energy expenditure, slowness and weakness will be considered as frail ${ }^{4}$.

Weight loss: Unintentional weight loss of $4.5 \mathrm{~kg}$ or more in the past 6 months ${ }^{4}$ and/or BMI of less than $18.5 \mathrm{~kg} / \mathrm{m}^{2}$ at the time of measurement ${ }^{18}$.

Exhaustion: 'a little' or 'none of the time' responses for the Short Form 12-item Survey (SF-12) question, "how much of the time during the past 4 weeks did you have a lot of energy?"'.

Low energy expenditure: A score $<73$ on the Physical Activity Score for Elderly (PASE) questionnaire ${ }^{19}$.

Slowness: The average of two readings in the $6 \mathrm{~m}$ fast gait speed test and a gait speed of $<0.65 \mathrm{~m} / \mathrm{s}$; the lowest quintile values stratified for gender and height will be used to classify the participants as 'Slow's.

Weakness: Hand grip strength stratified for sex and BMI will be measured using Jamar Hand Dynamometer. A measurement $<25 \mathrm{~kg}$ would be considered ' $W$ eak' ${ }^{\text {', }, 18}$.

\section{Fracture risk}

FRAX is a globally accepted tool to assess the risk fractures. The FRAX index without bone mineral density predicts the similar risk as the FRAX with $B M D^{20}$. FRAX indices specific for Sri Lanka will be calculated using the FRAX index calculator available.

\section{Tendency to fall}

Inability to walk and mobilize is an exclusion criterion for this component of the research.

The presence/absence of neurodegenerative disease, stroke and other diseases like deforming arthritis that will have a significant impact on activities of daily living will be gathered before continuing this component of research, as the analysis of cognitive deficit and tendency to fall may be affected by the presence of these conditions.

\section{a) Timed up and go (TUG) test}

Timed up and go (TUG) test will be used to assess the tendency to fall. The participants will be observed and timed as they stand up from a chair at the beginning of the walkway, walk $3 \mathrm{~m}$, turn around, walk back to the chair and sit down ${ }^{21}$. Regular footwear and customary walking aids would be used while the participant may walk at a comfortable and safe speed. A TUG time is the time in seconds a participant needed to complete the test. $\leq 13.5$ seconds will be considered normal (non-fallers) and $>13.5$ seconds will be considered those with high prediction for falls (fallers) ${ }^{22}$.

\section{b) Five Times Sit to Stand Test (FTSST)}

FTSST will be used to determine functional lower extremity strength and balance of each participant. This test measures in seconds, the time it takes an individual to stand up and sit down five times from a chair. No physical assistance is given. Subject starts with the back against the chair, arms crossed in front of the chest. Each stand will be counted aloud so that the patient remains oriented. The test will be stopped when the patient achieves the standing position on the 5 th repetition. $\leq 15$ seconds - normal; indicates functional level of lower extremity strength ${ }^{22}$.

\section{Cognitive assessment}

The Montreal Cognitive Assessment (MoCA) is an internationally accepted, widely used instrument used for assessment for mild cognitive impairment, which is validated for the Sri Lankan population and it takes about 10-15 minutes for the assessment ${ }^{23}$. Cognitive domains such as attention, concentration, 
memory, executive functions, visuo-constructional skills, calculations, orientation and conceptual thinking can be assessed separately using MoCA. The MoCA score ranges between 0-30 and a score of 24 or above will be considered normal and a score below 24 will be categorized as mild cognitive impairment ${ }^{23}$.

\section{Assessment for the risk of depression}

The geriatric depression score-short form (GDSS) which is validated for Sri Lankan population will be used to screen the population for depression. 10 or more points in GDS will be considered as "moderate depression", 8-10 points as "mild depression" warranting further assessment and a score below 8 as normal (non-depressed) ${ }^{24}$.

\section{Respiratory functions}

The inability to comprehend the instructions due to cognitive impairment and other contraindications for spirometry such as active respiratory infection, uncontrolled hypertension, history of ischemic heart disease, hemoptysis, pneumothorax, thoraco-abdominal surgery or pulmonary embolism will be considered as additional exclusion criteria for this component of research.

Respiratory functions will be assessed using Bioponys 3 spirometer quark PC KIT with USB. The same instrument will be used to perform measurements in all subjects. The subjects will be tested in the seated position. A nose clip will be applied to prevent air escaping through the nose during exhalation. Disposable mouth pieces will be utilized per individual to prevent cross-infection. The subjects will be asked to take a deep breath to maximal inspiration and exhale maximally in a slow expiration. The maneuver will be then be repeated with a forced exhalation. Each measurement will be repeated until three reproducible recordings are obtained. The measurement with highest reading will be taken as the test reading.

Slow vital capacity, forced vital capacity, forced expiratory volume in first second (FEV1), Peak expiratory flow rate (PEFR), MEF 75, MEF 50, MEF 25 will be obtained.

\section{Plan for data analysis}

\section{Demographic distribution and comorbidities}

The population demography according to sex, age, ethnicity, religion and marital status will be described in percentages. The prevalence of co-morbidities like diabetes, hypertension, dyslipidaemia, asthma and arthritis will be described.

\section{Nutritional and dietary assessment}

Anthropometric measurements will be used to classify the population according to WHO classification for South Asian population and the prevalence of each group; underweight, normal, overweight, obese and morbidly obese ${ }^{25}$. The body composition will be described using the anthropometric measurements height, weight, waist circumference, thigh circumference, calf circumference, mid-upper arm circumference and the skin fold thickness measured as biceps, triceps, subscapular and medial calf sites.

The portion sizes obtained by the 24-hour dietary recall will be described under five food categories: starch, proteins (legumes and animal products), fat, dairy products, fruits and vegetables ${ }^{26,27}$. The portion sizes consumed will be compared with the recommended portion sizes for the population ${ }^{28,29}$. The dietary intake will also be described in terms of energy calculated by theNutrisurvey 2000 software. The energy content of each food component will be calculated using standard energy values for the portion sizes and compared with the recommended intake of energy according to their age, body composition and physical activity.

\section{Assessment of frailty among the population}

The prevalence of frail, pre frail and no frail groups among the study population will be studied as the presence of $\geq 3$ components among the five fried components as "frail", 1-2 components present as "pre frail", no component present as "not frail"4.

\section{Cognitive assessment and depression screening}

Prevalence of mild cognitive impairment according to MoCA will be described. The population screened for depression will be described in terms of "mild depression" and "moderate depression" categories according to GDS"

\section{Risk of falls and osteoporosis}

The percentages of fallers and non-fallers in TUG (Timed Up and Go Test) test and those with good lower extremity strength and those without as to FTSST will be described. The association between cognitive functions and the risk of falling will be identified. The risk of fracture due to osteoporosis will be described by the FRAX index.

\section{Respiratory functions}

The spirometry findings among the population will be described using means. Restriction will be 
described as a SVC or FVC less than $80 \%$ of predicted. Airway obstruction will be categorized as FEV1/ FVC $\leq 70 \%$.

Correlation analysis will be conducted to assess the relationship between the components of the research. All data will be analysed using the SPSS 22 version.

\section{Discussion}

This study will be conducted to evaluate the health of the elders living in elderly homes in Colombo with a holistic approach. Individual studies have been conducted to assess different components like nutritional status in residents of elderly homes ${ }^{10}$, relationship between risk of falls and cognitive functions ${ }^{22}$, assessment of dependency in primary care using Barthel index ${ }^{30}$. There is paucity of data regarding lung function in elders in Sri Lanka. However, with the set of comprehensive tools to assess several components of health, this study will provide a holistic approach to health assessment in the residents. Many of the tools used in the study are already validated for Sri Lanka, like the GDS-S ${ }^{24}$ and the MoCA ${ }^{23}$ which improves precision of the data. However, some internationally accepted and widely used tools like the PASE, IPAQ used in this study have not yet been validated for the Sri Lankan population, which is a limitation. As the focus of this phase is on the residents of elders' homes, the planning and execution of the interventions for the deficits identified by this study would be relatively easy. However, the needs and the health care deficiencies of the elders in the community will have to be assessed separately, since this holistic approach may not be applicable for the community level due to high demand of resources and the time constraints in assessing community level elders using the same method.

\section{Outcome}

The findings of this phase will be used to develop health interventions to improve health status in the elderly population and the effectiveness of such interventions will be studied in the subsequent phases of the study. The data gathered in the first phase of this study shall be used to plan out an island wide study to assess the health status and the functional capacity of the elders living in Sri Lanka.

\section{Acknowledgements}

The National Secretariat for Elderly and all laboratory assistants of the Department of Physiology, Faculty of Medicine, University of Colombo.

\section{References}

1. United Nations, Department of Economic and Social Affairs, Population Division (2015). World Population Ageing 2015 (ST/ESA/SER.A/390). https://www.un.org/en/development/ desa/population/.../ageing/W PA2015_Report.pdf. Accessed on $21^{\text {st }}$ March 2017.

2. Cutler D, Richardson E, Keeler T, Staiger, D. Measuring the Health of the U.S. Population. Brookings Papers on Economic Activity. Microeconomics, 1997: 217-82.

3. Crimmins $E$, Saito Y. Change in the Prevalence of Diseases Among Older Americans: 1984-1994. Demographic Research, 2000: 3, Article 9. http://www.demographicresearch.org/Volumes/Vol3/9/. Accessed on $21^{\text {st }}$ March 2017.

4. Fried L, Tangen C, Walston J, Newman A, Hirsch C, Gottdiener, J, et al. Frailty in Older Adults: Evidence for a Phenotype. The Journals of Gerontology Series A: Biological Sciences and Medical Sciences 2001; 56(3): M146-M157.

5. Song X, Mitnitski A, Rockwood, K. Prevalence and 10-Year Outcomes of Frailty in Older Adults in Relation to Deficit Accumulation. Journal of the American Geriatrics Society 2010; 58(4): 681-87.

6. Sri Lanka Population and Housing Census 2012 | GHDx. (2019). http://ghdx. healthdata.org/record/sri-lankapopulation-and-housing-census-2012. Accessed on $20^{\text {th }}$ June 2019.

7. Ministry of National Policies and Economic Affairs, Department of Census and Statistics. National Survey on Self-Reported Health in Sri Lanka (2014).http://www. statistics. gov.lk/News/nBrief/National\% 20 Survey\% 20on\%20Self-reported\%20Health\%202014.pdf. Accessed on $20^{\text {th }}$ June 2019.

8. Katulanda P, Jayawardena M, Sheriff M, Constantine G, Matthews D. Prevalence of overweight and obesity in Sri Lankan adults. Obesity Reviews 2010; 11(11): 751-56.

9. Weerasuriya $\mathrm{N}$, Jayasinghe $\mathrm{S}$. A preliminary study of the hospital-admitted older patients in a Sri Lankan tertiary care hospital. Ceylon Medical Journal 2010; 50(1): 18-19.

10. Fernando $\mathrm{WH}$, Wijesinghe DG. Assessment of nutritional status and disease prevalence among elderly population in elderly homes in Kandy. Tropical Agricultural Research 2011; 21(3): 229-37.

11. Rathnayake K, Madushani P, Silva K. Use of dietary diversity score as a proxy indicator of nutrient adequacy of rural elderly people in Sri Lanka. BMC Research Notes. 2012; 5(1): 469.

12. Vellas B, Guigoz Y, Garry P, Nourhashemi F, Bennahum $D$, Lauque S, Albarede J. The mini nutritional assessment (MNA) and its use in grading the nutritional state of elderly patients. Nutrition 1999; 15(2): 116-22.

13. Washburn R, McAuley E, Katula J, Mihalko S, Boileau R. The Physical Activity Scale for the Elderly (PASE). Journal of Clinical Epidemiology 1999; 52(7): 643-51.

14. Craig C, Marshall A, Sjstrm M, Bauman A, Booth M, Ainsworth B, et al. International Physical Activity Questionnaire: 12-Country Reliability and Validity. Medicine \& Science in Sports \& Exercise 2003; 35(8): 1381-95. 
15. Katulanda P, Constantine G, Mahesh J, Sheriff R, Seneviratne $\mathrm{R}$, Wijeratne $\mathrm{S}$, et al. Prevalence and projections of diabetes and pre-diabetes in adults in Sri Lanka. Sri Lanka Diabetes, Cardiovascular Study (SLDCS). Diabetic Medicine 2008; 25(9): 1062-9.

16. ISAK manual, International standards for Anthropometric Assessment. (2006). 2001 ${ }^{\text {st }}$ Edition. Eds. Marfell-Jones M, Olds T, Stewart A, and Carte, L. Published by International Society for the Advancement of Kinanthropometry.

17. Freeman R, Wieling W, Axelrod F, Benditt D, Benarroch E, Biaggioni I et al. Consensus statement on the definition of orthostatic hypotension, neurally mediated syncope and the postural tachycardia syndrome. Clinical Autonomic Research 2011; 21(2): 69-72.

18. Andeen-Roche K, Xue Q, Ferrucci L, Walston J, Guralnik J, Chaves, $\mathrm{P}$ et al. Phenotype of Frailty: Characterization in the Women's Health and Aging Studies. The Journals of Gerontology Series A: Biological Sciences and Medical Sciences 2006; 61(3): 262-6.

19. Noguchi N, Blyth F M, Waite L M, Naganathan V, Cumming, $R$ $G$, Handelsman D, et al. Prevalence of the geriatric syndromes and frailty in older men living in the community: The Concord Health and Ageing in Men Project. Australasian Journal on Ageing 2016; 35(4): 255-61.

20. Gadam R, Schlauch K, Izuora K (2013). Frax prediction without BMD for assessment of osteoporotic fracture risk. Endocrine Practice 2016; 19(5): 780-4.

21. Podsiadlo D, Richardson S. The timed "Up \& Go": a test of basic functional mobility for frail elderly persons. Journal of the American Geriatrics Society 1991 39(2): 142-148.

22. Thanthrige RS, Dassanayake S, Dissanayake D. Relationship between increased risk of falling and cognitive impairment in residents of an elderly home in the Colombo district. Ceylon Medical Journal 2014; 59(1): 21-23.

23. Karunaratne S, Hanwella R, De Silva V. Validation of the Sinhala version of the Montreal Cognitive Assessment in screening for dementia. Ceylon Medical Journal 2011; 56(4): 147-53.

24. Kulathunga M, Umayal S, Somaratne S, Srikanth S, Kathriarachchi S, De Silva KR. Validation of the Geriatric Depression Scale for an elderly Sri Lankan clinic population. Indian Journal of Psychiatry 2010; 52(3): 254-56.

25. Barba C, Cavalli-Sforza T, Cutter J, Darnton-Hill I. Appropriate body-mass index for Asian populations and its implications for policy and intervention strategies. The Lancet 2004; 363 (9403): 157

26. Cleveland L, Cook DA, Krebs-Smith SM, et al. Method for assessing food intakes in terms of servings based on food guidance. Am J Clin Nutr 1997; 65(4): 1254S-63S.

27. Jayawardena R, Byrne N M, Soares M J, Katulanda P, Hills A P. Food consumption of Sri Lankan adults: an appraisal of serving characteristics. Public Health Nutrition 2013; 16(4): 653-8.

28. Nutrition Division, Ministry of Health. Food Based Dietary Guidelines for Sri Lanka, 2nd ed. Colombo: Nutrition Division, Ministry of Health. 2011 http://203.94.76.60/departmnt/ NutritionDivision/Nutrition\%20Guidelines/FBDGEnglish.pdf 10. Accessed on $20^{\text {th }}$ June 2019.

29. US Department of Agriculture. (1992). The Food Guide Pyramid. Home and Garden Bulletin no. 252. Washington, DC: USDA Center for Nutrition Policy and Promotion.

30. Nanayakkara C, Lekamwasam S. Validity of the 5-item Barthel Index in the assessment of physical dependence in the elderly. Asian J Gerontol Geriatr 2015; 10: 79-82. 